\title{
LA TÉCNICA DE ESCONDERSE EN LA COMEDIA DE ARISTOFANES
}

IDOIA MAMOLAR SÁNCHEZ

Centro Asociado Bizkaia de la UNED

\section{RESUMEN}

La autora estudia en este trabajo la técnica de esconderse ante la aparición de un personaje en la comedia aristofánica. Los ya presentes sobre la escena anuncian la entrada y se retiran para observar disimuladamente la actuación del recién llegado. Es éste un recurso que sirve, entre otras cosas, para crear expectación, de forma especial cuando el hecho de esconderse está ligado a situaciones dramáticas más o menos significativas. Este aspecto de la técnica, junto con otros (así, por ejemplo, la existencia o no de apartes, la duración dẹl escondite, o el hecho de que el personaje que entra, antes de ser visto, sea oído, o sentido de algún otro modo, utilizándose asi dos recursos para intensificar la expectación que despierta por sí misma toda entrada), son algunas de las cuestiones que se estudian.

El que los personajes presentes en escena anuncien una entrada ${ }^{1}$ y deliberadamente opten por «retirarse» ante la aparición que se produce es una técnica que Aristófanes uti-

' El concepto de «anuncio» que manejamos es el de TAPLIN, 1989: 71. Anuncio, según la definición del autor, es «todo lo que se dice sobre la aproximación de un personaje después de que esa aproximación ha sido primero vista (o percibida de otro modo) por alguien ya presente en escena»; respecto al hecho de que la entrada pueda ser advertida de otra forma, Taplin $(71, n .3)$ se refiere a la posibilidad de que el ruido o el olor indiquen la llegada de un personaje a escena. El anuncio, por tanto, no tiene por qué ser de naturaleza visual exclusivamente. Entre los que nos ocupan, una señal acústica advierte la aparición del personaje en Acarnienses 238-40 y $\mathrm{Paz}$ 232-5; sonido y olor se combinan en Ranas 312-5. En éstos dos últimos falta la declaración explícita de que el personaje entra en escena. 
liza en diversas ocasiones ${ }^{2}$. Sucede por primera vez en Acarnienses $238-40^{3}$, repitiéndose después en Paz 232-5, Tesmoforiantes 36-8, Ranas 312-5 y Asambleístas 27b-9.

Respecto al término «retirarse», con el que hemos designado la acción escénica que nos ocupa, requiere una explicación.

El texto no permite determinar si los personajes se ocultaban realmente en algún lugar - de modo que el recién llegado no los veía - , o no, y, si lo hacían, cuál era el sitio del escondite; las palabras que éstos utilizan para expresar su reacción indican sólo que

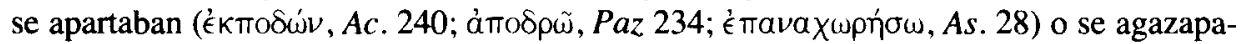

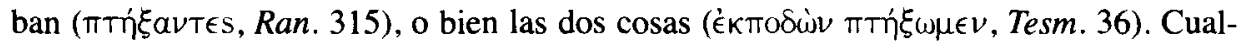
quier discusión al respecto nos parece poco fructífera. Lo importante es, a nuestro juicio, la tensión dramática que aporta la falta de contacto entre el personaje «oculto» y el que entra, ya sea ésta justificada escénicamente — en efecto, aquél se esconde, y éste otro no le ve - o resulte necesario apelar a la convención «sin ver a» aceptada por el espectador ${ }^{4}$.

Hecha esta aclaración, pasemos ahora al análisis propiamente dicho.

El recurso de esconderse ante la entrada de un personaje pone un acento particular sobre la entrada y - acabamos de adelantarlo - sirve al tiempo para crear expectación.

Puede tratarse, bien de una expectación general por el cómo y el cuándo se producirá el contacto, algo que está presente en todos los casos, aunque en Asambleístas sólo de forma muy reducida dada la extraordinaria brevedad (dos versos $-30 \mathrm{~s}$. - ) de la duración del escondite; o bien de una expectación añadida a ésta y que está asociada a situaciones más o menos significativas para la acción del drama, caso claro en Paz, Asambleistas y sobre todo en Acarnienses, donde intervienen, como espiado o espía, el protagonista y otra figura que representa una amenaza para el plan de aquél. Así, el pacífico Trigeo ( $\mathrm{Paz}$ ) contempla desde su escondite la puesta en acción del proyecto de Pólemo de machacar a las ciudades griegas dentro de un mortero (236-88); o el coro de acarnienses (Acarnienses), que se opone a la tregua con los lacedemonios, observa, silencioso y amenazante, la celebración de las Dionisias rurales (241-79), primera muestra de los beneficios de la paz privada de Diceópolis, una paz que representa el éxito, ya alcanzado,

${ }^{2}$ Esta técnica no es exclusiva de la comedia antigua. Está presente en la comedia de Menandro (Frost, 1988: 36, n. 7, cita algunos pasajes), y, aunque poco, la emplea también la tragedia, y esto ya desde el principio, es decir, desde Esquilo (Coéforos 10-21; vid. TAPLIN, 1989: 334-6). Sobre la cuestión insoslayable de un posible préstamo de la tragedia a la comedia, nos limitamos a señalar las dos posturas existentes: la de quienes piensan que se trata efectivamente de un préstamo (así, FraENKEl, 1962: 24; y RAU, 1967: 100, n. 9. que habla de préstamo y no de paratragedia); y la de quienes no ven la necesidad de hacer derivar del género trágico el empleo que hace la comedia de esta técnica (así, BAIN, 1977: 92). En fín, algunas consideraciones sobre la utilización del recurso en la comedia aristofánica se encuentran en FRAENKEL, 1962: 22-6, que estudia sólo los pasajes de Acarnienses, Tesmoforiantes y Ranas; un análisis comparativo de los dos primeros se encuentra en JOUANNA, 1997: 254-9.

${ }^{3}$ Para las citas y las referencias de número de verso de las comedias utilizamos la edición de Covion. Las traducciones de los pasajes son nuestras.

${ }^{4}$ Russo, 1984: 83, señala que en estos casos los personajes parecen esconderse detrás de un muro próximo a la fachada escénica (mencionado y utilizado de forma similar en Asambleístas 497 ss., apunta el autor), pero no es la única propuesta. Así, y por lo que se refiere a Paz, DEARDEN, 1976: 159, afirma que Trigeo se esconde «by the doorway"; COULON-V. DAELE, 1985: 108, y V. LeEUWEN, 1968: 43, anotan que se oculta en una esquina ( «ubi cerni nequeat a Belli deo", añade el segundo en la acotación); y OLson, 1998: ad 233-5, indica que se retira a un lado, fuera de la vista de Pólemo y Tumulto. Nos parecen suficientes estos ejemplos para ilustrar la polémica a la que nos referíamos. 
del plan del protagonista; por último, Praxágora (Asambleístas) se retira por miedo a que

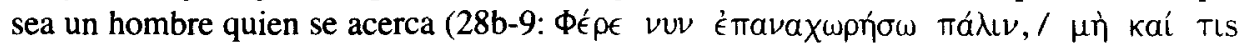

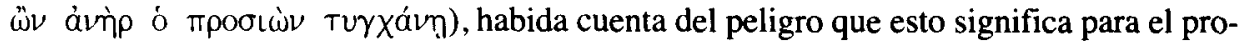
yecto de la heroína de que las mujeres acudan a la Asamblea disfrazadas de varones.

Cierta tensión de este segundo tipo se da también en Ranas, donde, al igual que en Asambleistas, aparece el motivo de la incertidumbre por la identidad del personaje que entra (Dioniso y Jantias se apartan con la aparente intención de asegurarse de que quienes se aproximan son los Iniciados que forman el coro - cf. 312-5, y sobre todo 318-22, donde de manera expresa el dios sugiere a su criado permanecer en silencio para saber con claridad de quién se trata: is ầ $\epsilon i \delta \tilde{u} \mu \epsilon \nu$ $\sigma a \phi \tilde{\omega} s, 322 \mathrm{~b}-$ ), aunque desprovisto ahora de la expectación añadida que supone la posibilidad de que el personaje sea un oponente. Por otro lado, el de Ranas es un momento importante en todas las comedias, a saber, la entrada del coro, y la persona que se esconde es central (Dioniso, acompañado, como sabemos, de su esclavo Jantias). El encuentro con los Iniciados constituye la antesala del final del viaje al Hades de la pareja; los Iniciados viven junto a la casa de Plutón y ellos darán a Dioniso la información que necesite (cf. 154-63 y 431-6), aunque estos detalles se olvidan durante tan largo escondite (316-430), y lo que importa es la actuación misma del coro.

Volviendo de nuevo sobre Acarnienses, la eficacia de la demora del contacto viene dada también por el hecho de posponerse un encuentro preparado de forma explícita y muy marcada en los versos previos, en los que tiene lugar la entrada del coro. El que éste irrumpa en la orquestra buscando al portador de la tregua (Anfíteo), con la intención de agredirle (204-36), crea la expectación del encuentro del coro con su oponente; sin embargo, la decisión de apartarse tomada por el corifeo (239 s.) cuando aparece «su hombre» ${ }^{5}$, frustra tal expectativa. El encuentro se demora hasta el verso 280 y constituye la «escena de batalla» ${ }^{6}$, donde los Acarnienses, coléricos, atacan a Diceópolis por su pacto con los lacedemonios, y éste intenta persuadirles para que le permitan exponer las razones de la tregua. El tiempo que media entre el anuncio y el enfrentamiento lo ocupa, como hemos dicho, la escena yámbica en la que Diceópolis celebra con los suyos las Dionisias rurales, interrumpidas por la guerra ${ }^{7}$.

${ }^{5} \mathrm{Al}$ menos en un primer momento, los Acarnienses, aparentemente, confunden a Diceópolis con Anfíteo («Ése mismo es al que buscamos», 239a, dice el corifeo al oír la petición de silencio que el protagonista formula dentro de la casa en 237); la exaltación de los Acarnienses a causa del pacto constituye, a nuestro juicio, un motivo plausible de este error, que, por otra parte, queda sin explicación en el texto. Fuera de sí, los Acarnienses atribuirían sin más la primera voz que oyen a la del hombre que buscan. Es ésta, por otra parte. una manera económica de provocar el encuentro del coro con su verdadero oponente (la celebración que el coro contempla en silencio deja claro, y esto es lo que importa, que Diceópolis es el responsable de la tregua), no habiendo necesidad de que la confusión inicial se aclare, ya que éste es un planteamiento lógico que la comedia no exige. En fin, el cambio de blanco del ataque del coro (de Anfíteo a Diceópolis) ha llamado la atención de los estudiosos, proponiendo distintas explicaciones para el mismo (vid., a modo de ejemplo, Súss, 1954: 123; Russo, 1984: 82-3; OLSON, 2002: ad 239-40).

${ }^{6}$ Término que utilizamos para la lucha típica entre un personaje y el coro, o entre dos personajes, a uno de los cuales apoya el coro, que aparece en algunas comedias tras la párodo (en $C a b$. coincide con ella) y que da paso al agón canónico o a una escena de tipo agonal (así, por ejemplo, en Acarnienses).

${ }^{7}$ MAZON, 1904: 25-7, relaciona la demora de la «batalla» mediante esta celebración (y la demora luego del discurso de defensa de Diceópolis) con el asunto espinoso tratado sobre la escena; es necesario - opina el autor - situar al héroe y a su pacto privado con el enemigo bajo una perspectiva burlesca, que reste seriedad al asunto y que permita que el espectador contemple sin acritud la figura y la actuación de Diceópolis; de ahí 
Sin ninguna duda, la falta de contacto entre el personaje espiado y el que espía tiene en Acarnienses un efecto dramático considerablemente mayor que en las «escenas de escondite» restantes.

En fin, la retirada que emprenden Eurípides y el Pariente ante la entrada del criado de Agatón en Tesmoforiantes es el único caso en que esa tensión ligada a situaciones más o menos significativas falta. En realidad, no hay ningún motivo para que ambos reaccionen de esta manera (a diferencia de lo que sucede en los pasajes restantes: lo hemos visto para Ranas y Asambleístas; en Paz Trigeo actúa movido por el miedo - 233b-5; y en Acarnienses, aunque no hay una motivación explícita, el deseo del coro de acechar a su adversario y atacarle por sorpresa, como en efecto ocurre -280 ss. - , resulta una explicación plausible), ni adquiere un significado dramático especial su separación, lo que hace resaltar el aspecto artificioso (teatral) que puede tener el recurso. De hecho, el contenido de las apostillas a las pomposas frases del espiado es fundamentalmente cómico, mientras que en $P a z$ y Ranas la broma se combina con observaciones más serias, $o$, si se prefiere, menos accesorias desde el punto de vista dramático.

Examinemos ahora otros aspectos de esta técnica.

En primer lugar - y acabamos de adelantarlo-, los personajes que toman la iniciativa de retirarse pueden permanecer en silencio (Acarnienses y Asambleístas) o pueden comentar en apartes la actuación del espiado ${ }^{8}$ ( $\mathrm{Paz}_{\text {, Tesmoforiantes y Ranas) }}{ }^{\text {; }}$ cuando son dos los personajes que observan a un tercero, los comentarios corren a cargo de ambos (Tesmoforiantes ${ }^{10}$ y Ranas). En cuanto al contenido de estas intervenciones, ya se ha señalado que lo gracioso siempre está presente: constituye casi el motivo único en Tesmoforiantes, y aparece junto a otros contenidos en Paz (reacción de asombro y de miedo de Trigeo ante la entrada de Pólemo - 238-41 - , e inquietud del protagonista por el plan del dios para los griegos - cf., p. ej., 263-7 y los comentarios siguientes -) y $R a$ nas (identificación de los personajes que se acercan -318-22-).

La extensión de los comentarios es breve - la mayoría no supera los dos versos -, y algunos de ellos están dirigidos al público (cf. Paz 244-5, 263-7, 276-9, 285-6), o incluso al propio espiado (cf. Paz 253-4). Lo primero constituye una típica ruptura de la ilusión escénica que pretende la complicidad de los espectadores; en cuanto a lo segundo, se trata de una apelación meramente externa, con la que el personaje que habla no busca establecer contacto.

la procesión grotesca y el ataque, en medio de la misma, del coro al protagonista, o la primera reacción de éste ante el asalto, preocupado por la marmita donde lleva el puré (284), en lugar de por su vida. Con independencia de que Mazon esté en lo cierto, es clara, no obstante, la expectación generada en los dos casos al posponerse la lucha y el discurso de Diceópolis a favor de los lacedemonios (éste se demora 150 versos, desde el cese de la pelea en 346 hasta 497 ).

${ }^{8}$ El uso de apartes en las «escenas de escondite» sólo está atestiguado en la comedia. En la tragedia, los personajes que se ocultan permanecen en silencio. Se trata de una diferencia importante en el uso de un mismo motivo por los dos géneros, diferencia que apunta BAIN, 1977: 91, pero no TAPLIN, 1989: 334-6. Por lo que se refiere a la comedia, el juego escénico de esconderse que acompaña al aparte hace más verosímil la convención de que una réplica oída por el público no lo sea por el personaje espiado.

${ }^{9}$ Paz 238-41, 244-5, 248-9, 251, 253-4, 257a, 258, 263-7, 271-3, 276-9 y 285-6; Ran. 318-22, 337-9 y 414-5; y Tesm. 45, 48b, 50b, 51b y 57b. En cuanto a los de Ran., ocupan sólo 10 de los 115 versos que dura el escondite, lo que significa que los personajes que espían (Dioniso y Jantias) permanecen en silencio la mayor parte del tiempo.

${ }^{10}$ En realidad, Eurípides sólo hace un comentarjo (45b), el resto corren a cargo del Pariente. 
En fin, con relación al comentario que Dioniso y Jantias hacen en Ran. 318-22, conviene aclarar que no constituye propiamente un aparte, ya que la entrada del coro de los Iniciados, por lo que parece, todavía no se ha producido. Que el coro permanecía aún invisible (al menos para los personajes del drama, quizá no para el público), lo sugieren las palabras de Jantias al oír la invocación a Yaco, que suena en 316-7: reconociéndolos por este grito (318), Jantias dice que los Iniciados «se divierten por aquí cerca» ( $\dot{\epsilon} V^{-}$

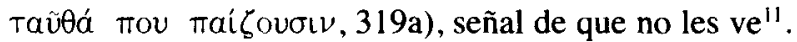

Muy probablemente en 323 el coro entraba en procesión cantando la estrofa del himno a Yaco $(323 / 4-36)^{12}$.

Por lo que se refiere al tiempo que se prolonga el escondite, varía según los casos. Poco dura el de Praxágora: desde que decide retirarse, como precaución ante la posibilidad de que sea un hombre quien se acerca, hasta que se cerciora de que se trata de mujeres y se dirige a ellas transcurren dos versos ( $A s$. 30-1, dístico con el que la Mujer primera acompaña su entrada y la de sus compañeras). En el otro extremo está Ranas: Dioniso y Jantias emprenden la retirada en 315 y así permanecen hasta 43013, es decir, hasta pasados más de 100 versos. En una posición intermedia se encuentran Tesmoforiantes (39-57), con un breve amago de contacto durante el escondite (cf. v. 51 : pregunta del criado de Agatón dejando ver que ha oído el comentario anterior del Parien-

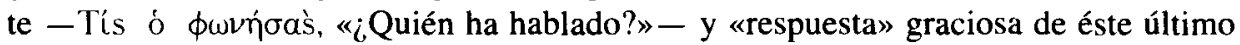

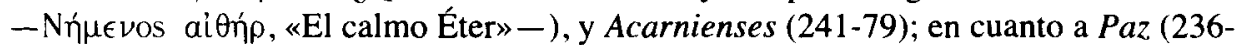
88 ), pasan 53, que abarcan varias escenas, lo que no ocurre en las otras ocasiones, en que el escondite no rebasa la escena en que aparece el personaje espiado. A lo largo de Paz 236-88, tienen lugar primero la aparición de Pólemo (236), después la de su esclavo Tumulto $(255 \mathrm{~b})$, que va $(262,275)$ y viene $(268,280)$, y, por último, la salida de los dos juntos (288). Paz es también el único caso en que el aislamiento no va seguido del contacto entre ambas partes: Pólemo y Tumulto se meten en la casa sin haberse percatado de la presencia de Trigeo.

Para terminar, hemos visto que la combinación de anuncio y reacción de los ya presentes de «retirarse» ante la entrada aparece en todos los casos. Pues bien, nos interesa señalar ahora la circunstancia de que en tres de ellos el anuncio tiene carácter acústico: como hemos dicho al inicio, se trata de Acarnienses (238-40; cf. además 237), Paz (232-5)

"De algún modo, Ran. 318-22 podría incluirse dentro del anuncio - acústico - de la entrada del coro. que comprendería así los versos 312-22, con la breve interrupción del grito a Yaco, oído, según lo dicho, fuera de escena. No obstante, por claridad nosotros hemos considerado como anuncio sólo los versos 312-5.

12 No obstante, hay quien piensa que el coro cantaba esta estrofa todavía fuera de escena, no apareciendo hasta la antístrofa (340 ss.). De esta opinión son, por ejemplo, MAzon, 1904: 143, y Russo, 1984: 329; en contra se muestran, entre otros, RADERMACHER, 1954: 183, y Dover, 1993: ad 323/4-53 (el hecho de que el comentario de Jantias en 338, como 313-4, se refiera al olor no es, observa éste último, argumento suficiente para sostener que el coro permanecía aún invisible: además, añade Dover, la calidad de la audición sería mejor si el coro cantaba ante los ojos de los espectadores).

${ }^{13}$ Ésta es la opinión, entre otros, de FraENkEl, 1962: 26, y ZIMMERMANN, 1985: 123, 132; también, por lo que parece, de GARCj́a LópEZ 1 1993: ad 416-439. No obstante, hay quien sostiene que la invitación del coro a burlarse juntos de Arquedemo (416-7) no es la sugerencia de un semicoro a otro, sino que está dirigida a Dioniso y Jantias (así, por ejemplo, RADERMACHER, 1954: 203, y DoVER, 1993: 66); según esta interpretación. el contacto entre el coro y la pareja tendría lugar en el v. 416 y no en 431, en el que Dioniso se dirige claramente a los Iniciados. 
y Ranas (312-5; cf. además 316-22). Tal observación queda recogida aquí por un motivo, a saber, porque se utilizan de forma simultánea dos recursos dramáticos que tienen la capacidad de crear expectación ante la nueva escena que ahora comienza. 1) Por un lado, la anticipación de la entrada de un personaje mediante señales acústicas $-\mathrm{y}$ mediante el olor en Ranas - provoca la expectativa de su aparición inmediata. Es un recurso del que el poeta se sirve en otras ocasiones; los ruidos y voces fuera de escena en la comedia aristofánica están estrechamente vinculados a la entrada de personajes: salvo contadas excepciones, tales sonidos anticipan la aparición de dramatis personae (así, por ejemplo, además de los casos que nos ocupan, en Caballeros 1326, Avispas 143, Ranas 603b-4, o Aves 92$)^{14}$. 2) Por otro, con la retirada de los ya presentes y la falta de contacto entre ambas partes el poeta logra prolongar el interés por el «encuentro».

Finalmente, nuestro estudio se ha centrado en un tipo de «escena de escondite» característico, aquél en el que los personajes presentes anuncian una entrada y advierten su decisión de retirarse. No obstante, es preciso aclarar que hay al menos otro ejemplo distinto de «escena de escondite» en la comedia. Nos referimos a Pluto 1097 ss.: en esta ocasión el personaje se esconde antes de que la nueva entrada se produzca, y ésta no recibe anuncio alguno; tampoco aquél advierte su decisión de retirarse. En efecto, el dios Hermes se presenta en escena y, sin decir nada, llama a la puerta de Crémilo y luego se esconde; cuando el esclavo de Crémilo abre, no le ve (1097-9a). Se trata de un escondite breve (no llega a tres versos), silencioso (Hermes no habla «aparte») y que resulta sobre todo una broma (cf. 1100b-2).

\section{BIBLIOGRAFIA}

\section{Ediciones, traducciones y comentarios}

Coulon, Victor: Aristophane, I-V, ed. de Coulon, V. y trad. al francés de VAN Daele, H., Paris, Les Belles Lettres.

- (1987): I. Les Acharniens - Les Cavaliers - Les Nuées, $12^{\mathrm{a}}$ ed., 1923 ( $\left.1^{\mathrm{a}} \mathrm{ed}.\right)$.

- (1985): II. Les Guêpes - La Paix, $8^{\mathrm{a}}$ ed., 1925 (1 $1^{\mathrm{a}}$ ed.).

- (1989): III. Les Oiseaux - Lysistrata, $9^{\mathrm{a}}$ ed., 1928 ( $1^{\mathrm{a}}$ ed.).

- (1973): IV. Les Thesmophories - Les Grenouilles, $7^{\mathrm{a}}$ ed., 1928 ( $1^{a} \mathrm{ed}$.).

- (1982): V. L'Assemblée des Femmes - Ploutos, $5^{2}$ ed., 1930 ( $1^{2}$ ed.).

DOVER, Kenneth (1993): Aristophanes. Frogs, ed. con introd. y com., Oxford, Oxford University Press.

Garcia LóPEZ, José (1993): Aristofanes. Las Ranas, intr., trad. al español y com., Murcia, Universidad de Murcia.

VAn Leeuvwen, J. (1968): Aristophanis Pax, ed. con introd. y com., $2^{\mathrm{a}}$ ed., 1906 ( $1^{\mathrm{a}}$ ed.), Leiden, A. W. Sijthoff.

${ }^{14}$ Del uso de ruidos y voces fuera de escena en la comedia de Aristófanes nos hemos ocupado en otro trabajo anterior (MAMOLAR, 2002). Una de las principales conclusiones de dicho estudio es precisamente la vinculación mencionada de tales sonidos con la entrada de personajes. 
Olson, S. Douglas (1998): Aristophanes. Peace, ed. con introd. y com., Oxford, Oxford University Press.

- (2002): Aristophanes. Acharnians, ed. con introd. y com., Oxford, Oxford University Press.

RADERMACHER, Ludwig (1954): Aristophanes' Frösche, ed. con introd. y com., $2^{\mathrm{a}}$ ed. (con adiciones de Kraus, W.), 1921 ( $1^{\mathrm{a}}$ ed.), Wien.

\section{Estudios}

BaIN, David (1977): Actors and Audience. A Study of Asides and Related Conventions in Greek Drama, Oxford, Oxford University Press.

DeARDEN, C. W. (1976): The Stage of Aristophanes, London, The Athlone Press.

FRAENKEL, Eduard (1962): Beobachtungen zu Aristophanes, Roma, Edizioni di Storia e Letteratura.

Frost, K. B. (1988): Exits and Entrances in Menander, Oxford, Oxford University Press.

JoUANNA, Jacques (1997): «Structures scéniques et personnages: essaj de comparaison entre les Acharniens et les Thesmophories", en THIERCY, Pascal - MENu, Michel (eds.), Aristophane: la langue, la scène, la cité (Actes du colloque de Toulouse, 17-19 mars 1994), Bari, Levante, pp. 253-68.

MAMOLAR, Idoia (2002): «Ruidos y voces fuera de escena en las comedias de Aristófanes», en García Soler, Ma José (ed.), TIMH乏 XAPIN. Homenaje al Profesor Pedro A. Gainzarain, Vitoria-Gasteiz, Universidad del País Vasco/Euskal Herriko Unibertsitatea, pp. 99-114.

MAZON, Paul (1904): Essai sur la composition des comédies d'Aristohane, Paris, Hachette.

RAU, Peter (1967): Paratragodia. Untersuchung einer komischen Form des Aristophanes, München, Beck.

Russo, Carlo Ferdinando (1984): Aristofane autore di teatro, $2^{2}$ ed. (aumentada y actualizada), 1962 ( $1^{\text {a ed. }}$ ), Firenze, Sansoni.

Sưss, Wilhelm (1954): «Scheinbare und wirkliche Inkongruenzen in den Dramen des Aristophanes». RhM 97, 115-59, 229-54, 289-316.

TAPLIN, Oliver (1989): The Stagecraft of Aeschylus. The Dramatic Use of Exits and Entrances in Greek Tragedy, $1^{\text {a }}$ ed. en rústica (corregida), 1977 ( $1^{\mathrm{a}} \mathrm{ed}$.), Oxford, Oxford University Press.

ZIMMERMANN, Bernhard (1985): Untersuchungen zur Form und dramatischen Technik der Aristophanischen Komödien. Bd. I: Parodos und Amoibaion, $2^{a}$ ed., 1984 ( $1^{a}$ ed.), Königstein/Ts, Hain. 